\title{
Research on the cultivation of Financial Talents in Vocational Colleges: from the perspective of "Internet Plus"
}

\author{
Hua Hefeng \\ Wuxi City College of Vocational Technology, Wuxi, Jiangsu Provice, China \\ Hfhua0802@126.com
}

Keywords: "Internet Plus”; finance major in vocational colleges; talent cultivation

\begin{abstract}
Since "Internet Plus" has been widely used in finance and education, finance major in vocational colleges should make adaptive changes by using technological tools to improve the quality of talent training. At present, the training of financial professionals in vocational colleges has some problems, such as unclear training orientation, not-updated knowledge, lacking changes in teaching forms, insufficient teacher training, and unclear characteristics of the major. Through "Internet Plus", it is hoped that the students' comprehensive quality can be improved, resources for financial curriculum teaching can be updated, practical financial training can be realized, and characteristics of finance major can be explored clearly. The application of "Internet Plus" will innovate the training mode of financial talents in vocational colleges, and will accurately guide the development of the finance major and promote its strength.
\end{abstract}

\section{Introduction}

In recent years, with the development of “Internet Plus" economy, the innovation speed and scale of Internet finance have been expanding. New Internet finance forms such as equity financing, P2P net loan and "the third party payment" have emerged. From the first year of Internet finance in 2013 to the present, the rapid development of Internet finance has created a huge demand for professionals. At present, there is a huge gap between the supply and demand of Internet financial talents. According to the research of China Vocational Education Yearbook (2016), the gap of talents in China's Internet financial industry will be more than one million in the next 5-10 years. In order to fill the gap between supply and demand, the finance major in colleges and universities should strengthen the training of talents, and at the same time, it needs to reform and upgrade the training mode of financial talents with the Internet thinking mode.

The finance major of vocational colleges focuses on training skilful financial personnel for the basic operational and marketing posts in the financial industry. But at present, the cultivation of financial talents in vocational colleges is facing internal and external pressures. First of all, from the perspective of the external environment, requirements for talents in commercial banks are constantly improving. Their basic requirement is a bachelors' degree. Vocational college students are difficult to meet this requirement. At the same time, technological changes in the banking sector are accelerating, therefore, the demand for employees in front-line application-oriented positions such as tellers and lobby managers is decreasing(Wang Zhuhua,2015), leaving less opportunities for vocational college students. And investment institutions such as securities and funds have higher requirements for professionals. Although insurance marketers have no academic qualifications, vocational college students are short of experience and relationship, and they have fewer chances to stay in insurance institutions for a long time. Secondly, from the perspective of internal training, there are some problems in finance major of vocational colleges, such as outdated curriculum, lagging behind the economic development, backward teaching methods, weak practical ability of teachers and so on(Li Guang, 2013). There is a big gap between professional skills of students and the requirements of basic financial jobs. However, with the rapid development of Internet finance, many Internet financial enterprises need a large number of skilled personnel for their operational and marketing posts. Therefore, the demand for financial talents of vocational colleges is increasing. 
Vocational colleges need to adapt to the requirements of Internet financial development and strive to train qualified front-line personnel with their own characteristics which are different from those of undergraduate students.

At present, "Internet Plus education" has been preliminarily applied in the teaching forms of micro lesson, moody class and flipped classroom. Internet education tools enable students to have more choices in learning time and arrangement, therefore, students' learning initiative can be improved, learning effect can be improved. "Internet Plus education" enables education to break through the limitation of time and space, optimize the allocation of educational resources, and promote the personalization of education (Gao Hong, 2016). The development of "Internet Plus education" has provided new ideas and methods for the cultivation of financial talents. It has raised new requirements for financial talents. Combining the two aspects, the concept of "Internet Plus" will provide a new path for the cultivation of financial talents in vocational colleges.

This paper sorts out and analyzes current problems in the training of financial professionals in vocational colleges, finds out the reasons for the problems, and puts forward the new financial skills training system which uses "Internet Plus" tools and technology to break through the obstruction of personnel training. Then, corresponding solutions are put forward from the perspective of the quality of students, curriculum resources, and teaching design.

\section{Analysis on the training of financial students in vocational colleges}

With the rapid development of the financial industry, many problems occur in the talent-training orientation, knowledge renewal, teaching form, teacher allocation of finance major in vocational colleges.

\subsection{Unclear Training orientation}

The training orientation of financial students in vocational colleges is different from that of ordinary universities. Vocational colleges focus on the frontline and sales positions of financial institutions. Basic financial skills and financial sales ability are their talent training objectives. Abilities of financial econometric analysis and strategically planning are not been cultivated with much effort. While, Undergraduate education of finance major usually focuses on mathematical analysis, quantitative analysis, macroeconomic analysis and other financial analysis capabilities. According to the survey, there are two main talent cultivation paths of finance majors in vocational colleges. The first way is to adopt a simplified version of undergraduate finance training program for finance major in vocational colleges. In the courses, commercial bank management and securities investment analysis are highlighted, and financial measurement and analysis are emphasized in the teaching content. The second way is that the finance major in vocational colleges adopts a similar training program with the accounting major, taking the same core courses. Only a few core courses such as commercial bank management and securities investment analysis are offered in the elective courses. The former way which takes undergraduate finance education makes the training of financial students in vocational colleges lose its own characteristics. Through it has undergraduate education form, it cannot maintain undergraduate education quality. As a result, vocational students will lack competitiveness in skills and employment, which brings crisis of legitimacy to the finance education in vocational colleges. As for the latter way, although it can save money and efforts in training and guarantee the students' professional skills and employment, this mode makes the financial major of vocational colleges become dispensable which devalue its existence greatly. Vocational college finance education has a greater ambiguity in the orientation, and it is not as clear as the majors of accounting and financial management. Finance major in vocational colleges need to clarify its orientation, grasp the situation and find breakthroughs in professional talent cultivation.

\subsection{Out-of-date knowledge}

Under the background of "Internet Plus" economy, the speed of financial innovation is accelerating, and the information as well as knowledge of finance industry are constantly updated. 
For the sake of maintaining stability and systematicness, the traditional finance teaching is not likely to timely update financial knowledge. On the one hand, the renewal and matching of teaching resources will take a lot of time. For example, the compilation and publication of textbooks need knowledge accumulation and systematic construction. Scattered practical knowledge can not form a systematic textbook, and innovative financial knowledge can not been collected into professional textbooks timely. On the other hand, college teachers have little contact with the latest financial innovation. Some teachers have not accumulated enough knowledge to explain financial innovation. As a result, their focus on professional financial knowledge is more confined to that of traditional business such as banking, securities, insurance and so on. The renewal speed of the course content of finance major lags behind the practice of financial industry development, which seriously affects the quality of student cultivation.

\subsection{Insufficient change in teaching form}

At present, the teaching of finance major in vocational colleges mainly adopts the form of lecturing with simple case study and discussions. Because of the popularization of higher education, vocational college students are various in the aspect of background, and their knowledge foundation is uneven, so it is very difficult to teach financial theory in classes. Some vocational colleges have offered courses such as financial manual operation, insurance certificate simulation training, stock exchange simulation training, but due to the training conditions, teachers' and students' foundation, the teaching effect is not satisfactory, and the effectiveness of students' skill training needs to be improved urgently. Finance major in vocational colleges is different from accounting and marketing majors, which requires more knowledge of statistics, probability theory and investment psychology. Appropriate theoretical teaching is necessary for training financial professionals. Moreover, theoretical teaching and skills training of financial students must be done simultaneously. However, as for the weak knowledge foundation and inadequate learning habits, the traditional theory teaching seems to be out of reach. Therefore, it is necessary to develop new ideas and methods by integrating new teaching methods and tools to consolidate students' financial knowledge so as to develop their financial skills and make them better adapted to financial jobs.

\subsection{Non-practical training of teachers}

Most teachers of the finance major in vocational colleges start their teaching career directly after they get their master's degree or doctor's degree from universities. Although they have enough theoretical knowledge, their practical ability is obviously insufficient. Vocational colleges emphasize the cultivation of skills, while financial teachers have obvious shortcomings in their experience and practical ability. Some vocational colleges sent their teachers to the financial companies or universities at home and abroad to further their study in practical skills. But because of the short study time and high confidentiality of financial institutions, it is difficult for teachers to obtain practical financial experience. In addition, financial students in vocational colleges are mainly employed in insurance companies, village banks and small investment institutions, while the traditional research directions of financial teachers are generally banks, brokerages, large-scale investment institutions, etc. Therefore, the practice of financial teachers needs to be changed according to the positions of vocational students.

\subsection{Vague professional features}

Finance major students in vocational colleges have different development fields, such as bank, securities, insurance and so on. A few colleges and universities also set up courses for real estate, art works, funds and other related fields. Because of the social reputation, professional strength, and other reasons, it is difficult for vocational college students to enter large commercial banks, securities companies and other financial institutions. Due to the inertia of financial professionals training, most of the financial students in vocational colleges are still taught by traditional courses about banking, securities and insurance. The finance majors of different vocational colleges have more similarities than differences, more repeatability than uniqueness, which causes much homogenization in competition and talent training. Therefore, financial major of vocational colleges 
needs to explore the characteristics of financial courses or professional directions in combination with geographical advantages and Internet learning tools, and make students understand the development of Internet financial instruments, such as equity crowd-funding, third-party payment, online auction, so as to achieve professional differentiation.

\section{The training system of financial talents under the background of "Internet Plus"}

The application of "Internet Plus" has introduced new ideas for the development of finance major in vocational colleges. We can inject Internet-related elements into training objectives, curriculum, teaching methods, and school enterprise cooperation, so as to create professional characteristics and form professional competitive advantages. For example, new Internet financial business will be able to hire more students from vocational colleges, thus alleviating the pressure that vocational students are not inclined to be hired by banks, brokerages and other traditional financial institutions. The open curriculum on the internet can provide new resources for finance major students. Through video teaching or live broadcasting teaching on the internet, we can share high-quality teachers' resources which can solve the problem of lacking of financial teachers with practical skills in vocational colleges. The forms of remote service and online question-and-answer supported by Internet technology can enrich cross-regional school-enterprise cooperation for vocational colleges by improving the scope and depth of school-enterprise cooperation. In a word, the application of "Internet Plus" can develop new financial courses, open up new teaching forms, share teachers' resources and create virtual school-enterprise cooperation for finance major in vocational colleges. These applications will greatly expand the prospect of financial development in vocational colleges and activate the vitality of financial major in vocational colleges.

The application of "Internet Plus" concept can help to cultivate students to be compound, innovative and professional talents(Guo Fuchuan, Xu Jiayang, 2017). In addition to traditional financial knowledge, compound talents also master information technology and knowledge about network security and so on. Innovative talents should have the creativity of financial innovation based on the Internet and the ability to develop new products, new business and new models of Internet finance. Professional talents refer to those who have subdivided knowledge of Internet finance, master some key technologies of Internet finance, and embody the uniqueness and scarcity of talents (See Figure 1).

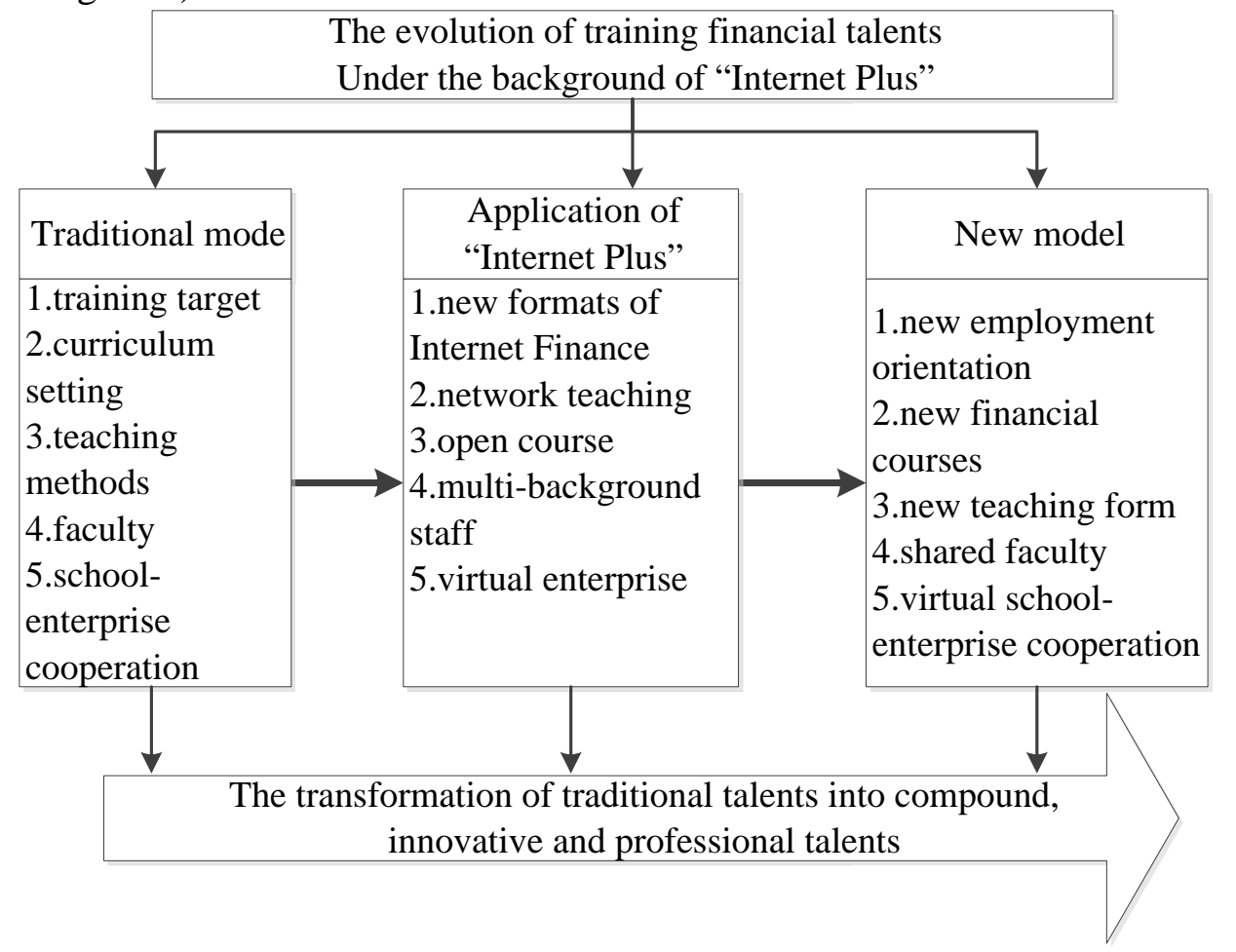

Figure 1 cultivation of financial talents under the "Internet Plus” background 
The application of "Internet Plus" can raise new ideas and explore new directions for finance major in vocational colleges. Through exploring the characteristics of finance major in vocational colleges and forming a pattern of dislocation competition with undergraduate finance major, vocational colleges can find a way suitable for their own development.

\section{Talent Training strategies}

Under the background of Internet economy, In order to transform and upgrade financial talent training, the cultivation program of vocational colleges should be based on Internet tools, adhere to the concept of openness and sharing, improve students' comprehensive quality, update financial curriculum resources, and try to realize financial teaching on the workplace.

\subsection{Improving students' comprehensive quality}

Vocational college students majoring in finance mainly work at front-line positions in financial institutions, which require qualifications of moral integrity, teamwork spirit, continuous learning and so on(Wu Wenying, 2013). Vocational colleges need to actively use Internet tools in the curriculum, teaching, school-enterprise cooperation and other aspects to improve the overall quality of students and enhance their comprehensive competitiveness. For example, colleges can adopt network courses or encourage innovative thinking, critical thinking, and decision-making tactics in the class to improve students' logical thinking ability and enhance students' depth of thinking. To improve students' comprehensive practical ability, we can also build a network platform to arrange comprehensive simulation training in teaching, so that students can flexibly carry out training both inside and outside the campus. Students' interest in learning and dreams of career should be respected in school-enterprise cooperation, and the students should be free to choose practice and exercise in different types of Internet financial enterprises. Students can also use Internet technology in the "school-in-enterprise" or entrepreneurial basements for a flexible long-distance practice, thereby fostering the ability of remote office and network teamwork. Improving students' quality is the key task of finance major in vocational colleges. Students' quality determines their growth space and height in the future. The application of Internet helps to broaden students' horizons, train students' ability and improve their competitiveness in the workplace.

\subsection{Updating financial curriculum resources}

Vocational colleges need to keep an eye on the development of Internet +finance. In the traditional curriculum, we can introduce knowledge of Internet finance, such as equity financing, P2P net loan and microfinance, and update the contents of the financial courses, so that students can understand the trend and innovation of financial industry. At the same time, it is necessary to set up some new courses, such as Internet financial operation, Internet financial laws and regulations, to introduce Internet financial products and services so as to prepare students for future work of Internet finance. However, we should not abandon the basic principles and methods of finance in the pursuit of the trend. Through decomposing and reconstructing the contents of Internet finance, we can help the students to understand the financial principles and analysis framework of internet finance, so that they can master the basic knowledge of finance and enhance their own ability of analyzing problems.

Vocational colleges should also make full use of the achievements of shared education which is developing rapidly in the world, such as "Coursera" which is initiated by Stanford University, UC Berkeley, Duke University and other institutions, and "edx" which is supported by the Massachusetts Institute of Technology, Harvard University, and University of California. Moreover, many Chinese universities also have their own open online courses. These open curriculum resources have made up for the gaps of courses between schools. By utilizing these advanced curriculum platforms, the financial major in vocational colleges can enrich their curriculum resources, facilitate students to master advanced knowledge and broaden their vision. 


\subsection{Teaching in real financial situations}

According to the job responsibilities, the teaching contents of finance major in vocational colleges are generally designed to highlight practicality and operability. And a lot of attention is paid to both theoretical and practical knowledge in the teaching processes. However, the financial classes are often faced with two difficulties, i.e. inadequate theoretical teaching and students' weak ability of understanding and inadequate application of financial theory. Thus the training effect is not satisfactory. Only through simple software simulation students cannot experience the real financial market. Therefore, through the application of "Internet Plus" , we can ease the strain of professional education in finance major. In order to enhance the persuasiveness of financial knowledge and make students deeply impressed with the basic knowledge of finance, network teaching resources such as open courses, micro-courses and Mooc-courses are introduced in the courses. For some important knowledge, teachers can use videos in which business managers or finance experts explain financial affairs to help students in learning. For investment practice, students are encouraged to participate in the simulated stock speculation contests supported by various securities companies, so that they can experience the price fluctuations in the real market and understand the real emotional ups and downs. In the practice of banking activities, students are guided by the "Provincial Competition" of the provincial Education Department and the "National Competition" of the Ministry of Education of China to practice the banking business skills and master the real banking operation techniques. The teaching of finance major should guide students to understand the real operations of the financial market, and realize the combination of theory and practice.

\subsection{Exploring development characteristics of the finance major}

Due to the distinctions between vocational colleges and undergraduate universities in the aspects of source of students, teaching conditions and research strength, the development of finance major in vocational colleges should take the differentiation strategy. Different colleges and universities need to explore different ways of professional development in combination with regional, industrial and cultural characteristics. The introduction of "Internet Plus" contributes to the differentiated development of financial major in vocational colleges. Taking the regional characteristics as an example, each city in Jiangsu Province has its own unique industries. For example, colleges in Wuxi can study investment on Yixing purple clay pottery, colleges in Yangzhou can develop investment on lacquerware, and colleges in Lianyungang can develop investment on crystal stones. In the past, the development of these fields was restricted by the lack of teachers and training conditions. "Internet Plus" can introduce teachers and equipment flexibility into classroom by means of live broadcast teaching, virtual reality (VR), and AR, thus helps colleges to develop their finance major in different directions according to their own regional advantages.

\section{Conclusion}

The Internet era brings both challenges and opportunities to finance major in vocational college. The introduction of "Internet Plus" can innovate the talent training objectives, improve professional curriculum, test the network teaching mode, and further explore the development of students' quality, teacher training and professional characteristics. In the future, with further development of the Internet, finance major of vocational colleges will further explore ways to cultivate talents by using network technology to adapt to the trend of the times and help the growth of their students.

\section{Acknowledgements}

This paper is supported by Youth Fund Project of Humanities and Social Sciences of the Ministry of Education of China (14YJC880021), Educational reform project (JG1619). 


\section{References}

[1] Gao Hong. Opportunities. (2016) challenges and Countermeasures Faced by higher education in the context of “Internet Plus". Heilongjiang Researches on Higher Education, 11,78-81.

[2] Guo Fuchuan, Xu Jiayang. (2017)Research on Internet financial talents training system based on super network model). Journal of Vocational Education, 24,34-39.

[3] Li Guang. (2013)Discussion on training mode of investment and finance professionals in Higher Vocational Colleges). China Adult Education, 2,172-174.

[4] Wang Zhuhua. (2015)The impact of banking development on the training of applied financial talents and Countermeasures). Vocational and Technical Education, 29,12-15.

[5] Wu Wenying. (2013)Discussion on comprehensive quality training of financial professionals in Higher Vocational Colleges). Education and Vocation, 17,111-113. 